\title{
Increased level of nucleolin confers to aggressive tumor progression and poor prognosis in patients with hepatocellular carcinoma after hepatectomy
}

\author{
XiaoDong Guo ${ }^{1 \dagger}$, Lu Xiong ${ }^{2 \dagger}$, Lingxiang Yu ${ }^{1}$, Ruisheng $\mathrm{Li}^{1}$, ZhaoHai Wang ${ }^{1}$, Bo Ren ${ }^{1}$, JingHui Dong ${ }^{1}$, Boan Li ${ }^{1 *}$ \\ and Dadong Wang ${ }^{3 *}$
}

\begin{abstract}
Background: Nucleolin, as a multifunctional protein, has been demonstrated to play an oncogenic role in human hepatocellular carcinoma (HCC). The aim of this study was to investigate the expression pattern of nucleolin in HCC and determine its correlation with tumor progression and prognosis.

Methods: Nucleolin expression at both mRNA and protein levels in HCC and adjacent nonneoplastic tissues were respectively detected by quantitative real time polymerase chain reaction (Q-PCR), immunohistochemistry and western blotting.

Results: Nucleolin expression, at both mRNA and protein levels, was significantly higher in HCC tissues than in the adjacent nonneoplastic tissues (both $\mathrm{P}<0.001$ ). In addition, the elevated nucleolin expression was markedly correlated with advanced tumor stage $(P=0.001)$, high tumor grade $(P=0.02)$ and serum AFP level $(P=0.008)$. Moreover, HCC patients with high nucleolin expression had shorter 5-year disease-free survival and shorter 5-year overall survival than those with low expression (both $\mathrm{P}<0.001$ ). Furthermore, the Cox proportional hazards model showed that nucleolin expression was an independent poor prognostic factor for both 5 -year disease-free survival (hazards ratio $[H R]=3.696,95 \%$ confidence interval $[C l]=1.662-8.138, P=0.01)$ and 5 -year overall survival $(H R=3.872$, $\mathrm{Cl}=1.681-8.392, \mathrm{P}=0.01)$ in HCC.
\end{abstract}

Conclusion: These results showed that the markedly and consistently increasing expression of nucleolin may be associated with aggressive characteristics of HCC, and implied that nucleolin expression may serve as a promising biochemical marker for predicting the clinical outcome of patients with this malignancy.

Virtual Slides: The virtual slide(s) for this article can be found here: http://www.diagnosticpathology.diagnomx.eu/ vs/13000_2014_175.

Keywords: Hepatocellular carcinoma, Nucleolin, Expression, Tumor progression, Prognosis

\section{Background}

Hepatocellular carcinoma (HCC), accounts for approximately $90 \%$ of liver cancers, is the third cause of cancer mortality worldwide, with 700,000 new cases annually [1]. Nearly $85 \%$ cases with HCC occur in developing countries of East Asia and sub-Saharan Africa [2]. In

\footnotetext{
*Correspondence: Iba302@163.com; ddwang304@163.com

${ }^{\dagger}$ Equal contributors

³02 Hospital of PLA, Beijing 100039, China

${ }^{3}$ Department of Hepatobiliary and Pancreaticosplenic Surgery, the First

Affiliated Hospital of General Hospital of PLA, Beijing 100048, China

Full list of author information is available at the end of the article
}

China, HCC is the second leading cause of cancer-related death among men. Its five-year postoperative survival rate is only $30 \%$ to $40 \%$ [3]. As a highly aggressive solid tumor, HCC is characterized by fast infiltrating growth, early metastasis, high-grade malignancy, and poor prognosis. Currently, hepatic resection is the first choice for patients suffering with HCC, however, the long-term survival remains unsatisfactory mainly due to a high incidence of postoperative metastasis and recurrence, and the high resistance of HCC to chemotherapy [4]. Accumulating studies have demonstrated that the progression of HCC is a complicate process which is associated with environmental

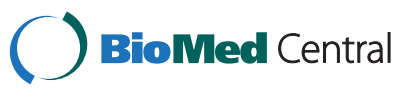

(c) 2014 Guo et al.; licensee BioMed Central Ltd. This is an Open Access article distributed under the terms of the Creative Commons Attribution License (http://creativecommons.org/licenses/by/4.0), which permits unrestricted use, distribution, and reproduction in any medium, provided the original work is properly credited. The Creative Commons Public Domain Dedication waiver (http://creativecommons.org/publicdomain/zero/1.0/) applies to the data made available in this article, unless otherwise stated. 
factors (such as infection with HBV and alcoholic liver disease) and genetic/epigenetic alterations [5]. However, the molecular mechanism of the tumor development and progression in HCC has not been fully elucidated. Thus, it is extremely necessary to illustrate the mechanisms underlying hepatocarcinogenesis and the process of tumor invasion and tumor metastasis, and further identify efficient molecular markers for early diagnosis and prognosis as well as valuable therapeutic targets.

Nucleolin is a multifunctional and mobile protein which can shuttle among the nucleolus, nucleoplasm, cytoplasm, and cytoplasmic membrane [6]. It is originally identified by Orrick et al. [7] in 1973, and then, the same protein was extracted from ovary cells of Chinese hamster, and several other eukaryotic cells, including human, rat, mouse, and chicken [8]. Nucleolin has an apparent molecular mass of $100-110 \mathrm{kDa}$ as determined by SDS-PAGE and a calculated molecular mass of $76-77 \mathrm{kDa}$ as predicted by the amino acid sequence. This difference may be due to posttranslational modifications and a high content of negatively charged amino acids in the N-terminal part of nucleolin [9]. Functionally, it is implicated in many aspects of DNA metabolism, and participates extensively in RNA regulatory mechanisms, including transcription, ribosome assembly, mRNA stability and translation, and microRNA processing [10]. Nucleolin is also involved in pathological processes, particularly cancer. It is overexpressed in highly proliferative cells, especially in several malignant cells, including neuroblastoma, cutaneous melanoma, pediatric intracranial ependymoma, breast cancer, lung cancer, colon cancer [11-16]. Nucleolin functions as a oncogene and regulates the abilities of cancer cells to grow and proliferate, overcome senescence, evade apoptosis and the immune system, invade and metastasize other tissues and promote angiogenesis. To our interests, Bao et al. [17] identified nucleolin as a candidate biomarker for diagnosis of HCC by quantitative proteomic analysis of a paired human liver healthy versus carcinoma cell lines with the same genetic background; Meng et al. [18] further found that the downregulation of nucleolin expression may inhibit the growth of HCC cells in vitro. These previous studies suggest that nucleolin plays a role in HCC. However, its clinical significance remains unclear. Therefore, the aim of the current study was to investigate the expression pattern of nucleolin in HCC and determine its correlation with tumor progression and prognosis.

\section{Methods}

Patients and tissue samples

The study was approved by the Research Ethics Committee of 302nd Hospital of PLA, Beijing, China. Informed consent was obtained from all of the patients. All specimens were handled and made anonymous according to the ethical and legal standards.
A total of 130 patients with primary HCC who underwent a curative liver resection at the 302nd Hospital of PLA, Beijing, China, were included in this retrospective study. Tissues used in the study were retrieved from the tissue bank of the Department of Pathology in the 302nd Hospital of PLA. These patients were diagnosed as HCC between March 2001 and February 2006. None of the patients recruited in this study had chemotherapy or radiotherapy before the surgery. HCC diagnosis was based on World Health Organization (WHO) criteria [19]. Tumor differentiation was defined according to the Edmondson grading system [20]. Liver function was assessed using the Child-Pugh scoring system [21]. Tumor staging was determined according to the sixth edition of the tumor-nodemetastasis (TNM) classification of the International Union against Cancer [22]. The clinicopathological features of 130 patients are summarized in Table 1 . In addition, 30 matched HCC specimens (5 TNM stage I, 8 TNM stage II, 12 TNM stage III, and 5 TNM stage IV) and adjacent nonneoplastic liver tissues were collected between April 2008 and March 2010, snap-frozen in liquid nitrogen and stored at $-80^{\circ} \mathrm{C}$ following surgery for real-time quantitative RT-PCR assay and western blot analysis.

The median follow-up period of 130 patients with primary HCC was 8.6 years. Postoperative surveillance included routine clinical and laboratory examinations every third month, computed tomography scans of the abdomen, and radiographs of the chest every third month. After 5 years, the examination interval was extended to 12 months.

\section{Quantitative RT-PCR}

To measure the mRNA expression levels of nucleolin, total RNA was extracted from frozen liver tissues using TriZol reagent (Invitrogen) following the manufacturer's instructions. Two micrograms of total RNA was subjected to reverse transcription to synthesize cDNA using the ProtoScript M-MuLV Taq RT-PCR Kit (New England Biolabs), according to the manufacture's instruction, followed by real-time PCR using the TransStart Green qPCR SuperMix (TransGen Biotech). The primer sequences of nucleolin were forward primer, 5' - GCA CTT GGA GTG GTG AAT CAA A-3', reverse primer, 5' - AAA TGC ATA CCC TTT AGA TTT GCC-3'. The transcription of GAPDH was used as an internal control for normalization. nucleolin expression levels were calculated relative to GAPDH using the delta-delta cycle threshold method [23].

\section{Western blot}

The Western blot protocol and semiquantitative analysis were carried out following the protocol of $\mathrm{Xu}$ et al. [24]. nucleolin antibody (mouse monoclonal antibody, dilution 1:100, 4E2, \#ab13541, Abcam Inc., Cambridge, UK) was used, and GAPDH antibody (CW0266, dilution 1:1,000, CoWin Biotech) was used as internal control. 
Table 1 Clinicopathological features and the expression of nucleolin in $\mathbf{1 3 0}$ hepatocellular carcinoma patients

\begin{tabular}{|c|c|c|c|c|}
\hline \multirow{2}{*}{$\begin{array}{l}\text { Clinicopathological } \\
\text { features }\end{array}$} & \multirow[t]{2}{*}{ Case } & \multicolumn{2}{|c|}{$\begin{array}{l}\text { Nucleolin expression } \\
\text { frequency }(n, \%)\end{array}$} & \multirow[t]{2}{*}{$\mathbf{P}$} \\
\hline & & High & Low & \\
\hline \multicolumn{5}{|l|}{ Age (years) } \\
\hline$\leq 50$ & 72 & $40(55.56)$ & $32(44.44)$ & \multirow{2}{*}{ NS } \\
\hline$>50$ & 58 & $28(48.28)$ & $20(51.72)$ & \\
\hline \multicolumn{5}{|l|}{ Gender } \\
\hline Male & 96 & $58(60.42)$ & $42(39.58)$ & \multirow{2}{*}{ NS } \\
\hline Female & 34 & $20(58.82)$ & $14(41.18)$ & \\
\hline \multicolumn{5}{|l|}{ Serum AFP } \\
\hline Positive & 72 & $58(80.56)$ & $14(19.44)$ & \multirow{2}{*}{0.008} \\
\hline Negative & 58 & $20(34.48)$ & $38(65.52)$ & \\
\hline \multicolumn{5}{|l|}{ Tumor stage } \\
\hline $\mathrm{T} 1$ & 23 & $0(0)$ & $23(100.00)$ & \multirow{4}{*}{0.001} \\
\hline $\mathrm{T} 2$ & 40 & $23(57.50)$ & $17(42.50)$ & \\
\hline T3 & 52 & 40 (76.92) & $12(23.08)$ & \\
\hline T4 & 15 & $15(100.00)$ & $0(0)$ & \\
\hline \multicolumn{5}{|l|}{ Tumor grade } \\
\hline G1 & 31 & $12(38.71)$ & $19(61.29)$ & \multirow{3}{*}{0.02} \\
\hline G2 & 76 & $48(63.16)$ & $28(36.84)$ & \\
\hline G3 & 23 & $18(78.26)$ & $5(21.74)$ & \\
\hline \multicolumn{5}{|l|}{ Growth pattern } \\
\hline Trabecular & 101 & $59(58.42)$ & $42(41.58)$ & \multirow{2}{*}{ NS } \\
\hline Nontrabecular & 29 & 19 (65.52) & $10(34.48)$ & \\
\hline \multicolumn{5}{|l|}{ Cirrhosis } \\
\hline Yes & 86 & $50(58.14)$ & $36(41.86)$ & \multirow{2}{*}{ NS } \\
\hline No & 44 & $28(63.64)$ & $16(36.46)$ & \\
\hline \multicolumn{5}{|c|}{ Underlying liver disease } \\
\hline Alcoholic & 25 & $10(40.00)$ & $15(60.00)$ & \multirow{4}{*}{ NS } \\
\hline Hepatitis B & 49 & $28(57.14)$ & $21(42.86)$ & \\
\hline Hepatitis C & 35 & $28(80.00)$ & $7(20.00)$ & \\
\hline Unknown & 21 & $12(57.14)$ & $9(42.86)$ & \\
\hline
\end{tabular}

Note: 'NS' refers to the differences among groups have no statistical significance.

\section{Immunohistochemistry analysis}

Immunohistochemical staining was carried out following the protocol of our previous study [25-27]. The primary antibody against nucleolin: mouse monoclonal antibody (4E2, \#ab13541, Abcam Inc., Cambridge, UK), dilution 1:100. Secondary antibody for the detection of primary antibody: anti-goat IgG (\#sc-2028, Santa Cruz Biotechnology, Inc. USA). The negative controls were processed in a similar manner with PBS instead of primary antibody. The positive nucleolin expression confirmed by western blotting was used as positive controls for immunostaining.

Following a hematoxylin counterstaining, immunostaining was scored by two independent experienced pathologists, who were blinded to the clinicopathological parameters and clinical outcomes of the patients. The scores of the two pathologists were compared and any discrepant scores were reconciled through re-examining the stainings by both pathologists to achieve a consensus score. The number of positive-staining cells showing immunoreactivity in the nucleus, cytoplasm and/or cytoplasmic membrane for nucleolin in ten representative microscopic fields was counted and the percentage of positive cells was calculated. The percentage scoring of immunoreactive tumor cells was as follows: 0 (0\%), 1 (1-10\%), 2 (11-50\%) and 3 (>50\%). The staining intensity was visually scored and stratified as follows: 0 (negative), 1 (weak), 2 (moderate) and 3 (strong). A final score was obtained for each case by multiplying the percentage and the intensity score. Therefore, tumors with a multiplied score of less than 5.62 (median of total scores for nucleolin) were considered to be low nucleolin expressers; all other scores were considered to be high nucleolin expressers.

\section{Statistical analysis}

The software of SPSS version13.0 for Windows (SPSS Inc, IL, USA) and SAS 9.1 (SAS Institute, Cary, NC) was used for statistical analysis. Fisher's exact test [28] and the $\mathrm{X}^{2}$ test [29] were performed to assess associations between nucleolin expression and clinicopathological parameters. The Kaplan-Meier method [30] was used for survival analysis, and differences in survival were estimated using the log-rank test [31]. A multivariate survival analysis was performed for all parameters that were significant in the univariate analyses using the Cox regression model [32]. Differences were considered statistically significant when $P$ was less than 0.05 .

\section{Results}

Increased expression of nucleolin mRNA and protein in HCC Quantitative RT-PCR was performed to compare the expression level of nucleolin mRNA between 30 matched tumor-normal specimens of HCC. We found that 22 of 30 patients $(73.33 \%)$ had higher nucleolin mRNA expression in HCC tissues than in adjacent nonneoplastic liver tissues. Statistical analysis showed that the relative expression of nucleolin mRNA in HCC tissues was significantly higher than in the adjacent nonneoplastic liver tissues $(2.61 \pm 1.00$ vs. $1.22 \pm 0.76, \mathrm{P}<0.001$; Figure $1 \mathrm{~A}$ and $\mathrm{B})$. In addition, nucleolin expression at protein level in HCC and adjacent nonneoplastic liver tissues were also measured by Western blotting. Similar with the quantitative RT-PCR results, the expression levels of nucleolin protein in HCC tissues were markedly higher than those in the adjacent nonneoplastic liver tissues ( $3.17 \pm 1.06$ vs. $1.89 \pm 0.79, \mathrm{P}<0.001$; Figure $1 \mathrm{C}$ and $\mathrm{D})$.

In order to confirm the subcellular localization of nucleolin protein in HCC tissues, immunohistochemical 


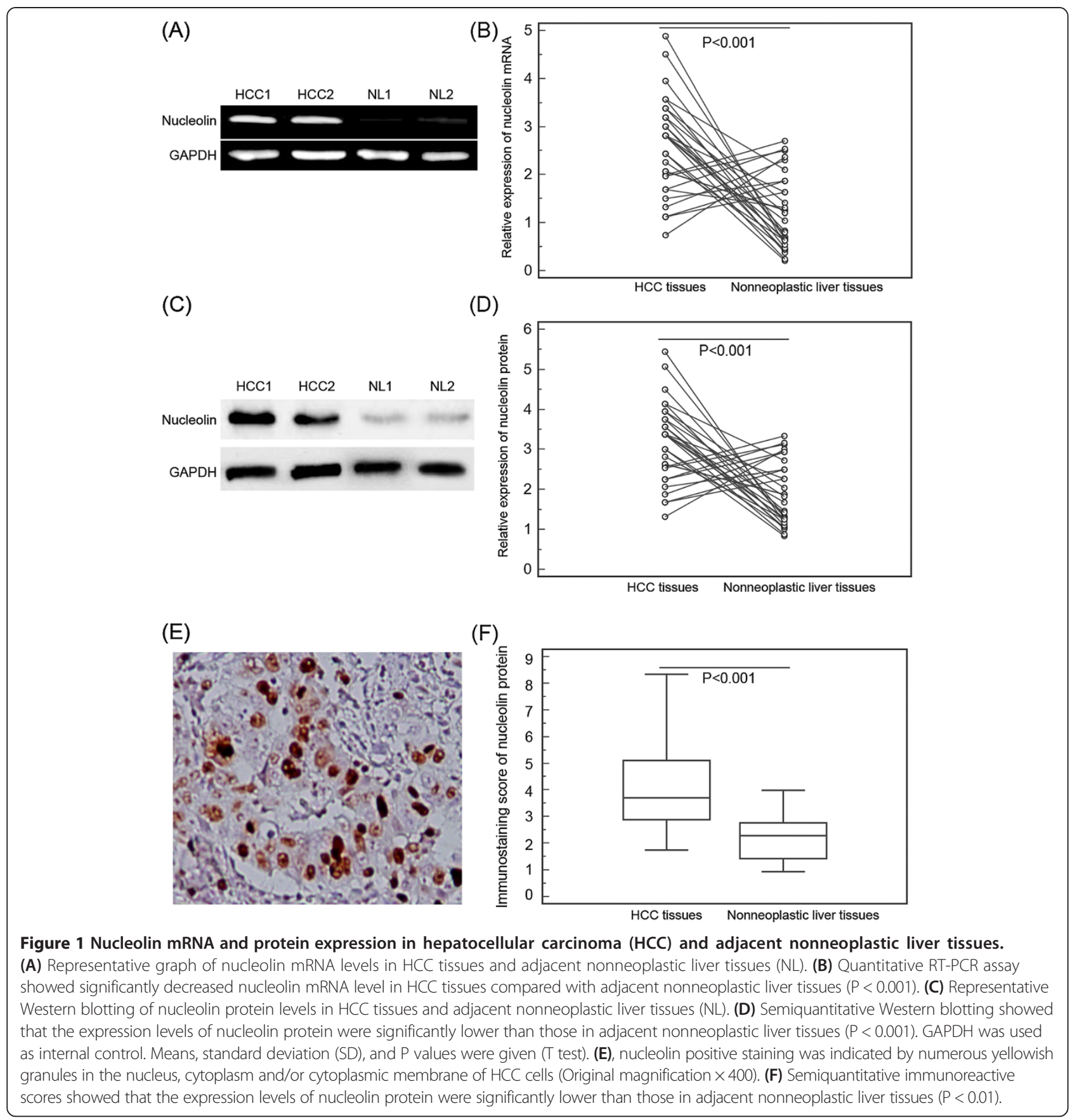

analysis was performed using 130 matched tumor-normal specimens of HCC. The immunostaining for nucleolin was observed in the nucleus, cytoplasm and/or cytoplasmic membrane of HCC cells (Figure 1E). The immunostaining scores of nucleolin protein in HCC tissues were significantly higher than those in adjacent nonneoplastic liver tissues $(5.19 \pm 3.17$ vs. $2.43 \pm 1.34, \mathrm{P}<0.001$; Figure $1 \mathrm{~F})$. In $130 \mathrm{HCC}$ tissues, 78 (75/130, 60.00\%) showed high nucleolin expression, while $52(40.00 \%, 52 / 130)$ displayed low nucleolin expression.

\section{Association of nucleolin expression with the clinicopathological features of HCC}

To determine whether nucleolin protein expression levels are indicative of the state of HCC progression, we analyzed the association between nucleolin immunostaining scores and tumor stage, tumor grade, serum AFP level, presence of cirrhosis, underlying liver disease including alcohol abuse, viral hepatitis $\mathrm{B}$ and $\mathrm{C}$, gender, and age. As summarized in Table 1, the statistically significant correlations were observed between nucleolin expression and 

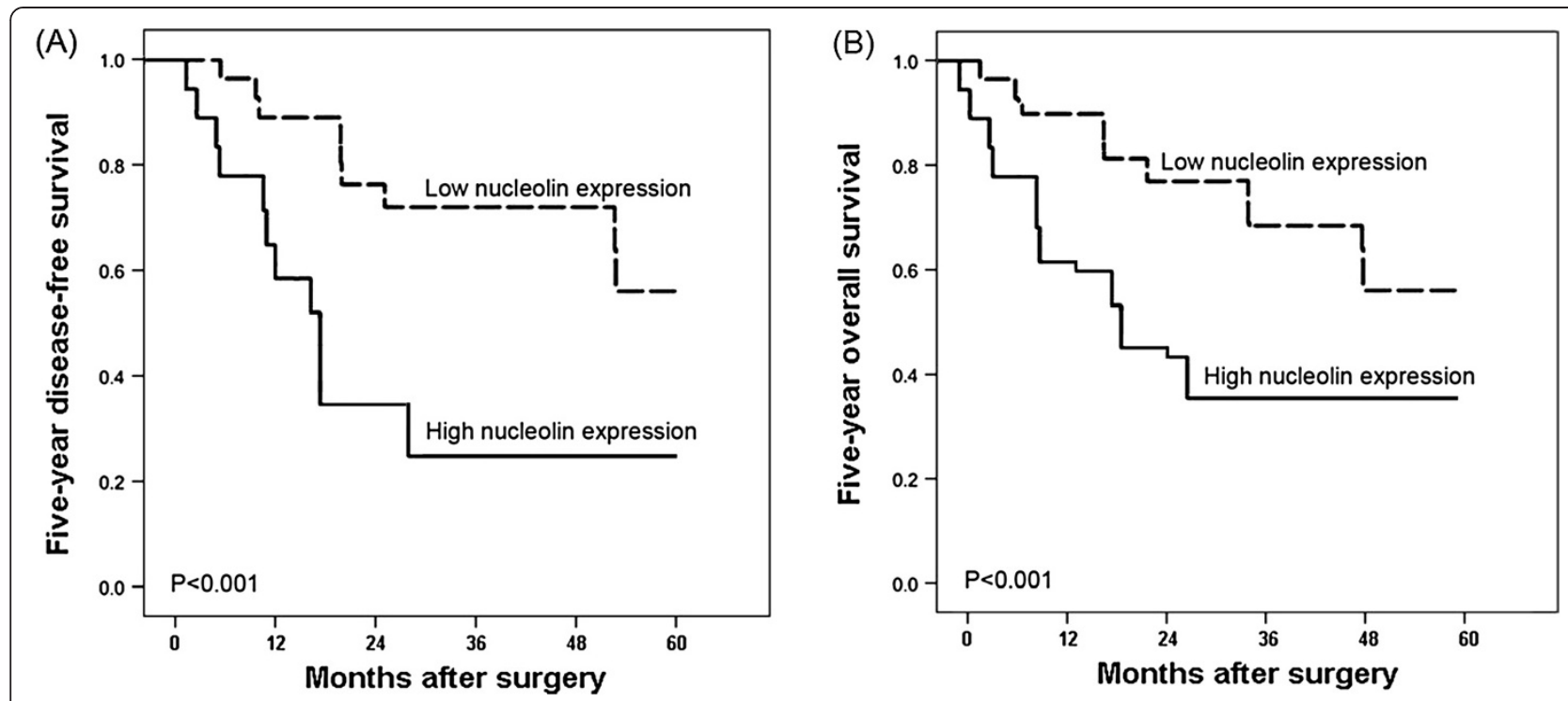

Figure 2 Kaplan-Meier survival curves for nucleolin expression in hepatocellular carcinoma (HCC) patients. HCC patients with high nucleolin expression had shorter 5-year disease-free survival (A) and shorter 5-year overall survival (B) than those with low expression (both $\mathbf{P}<0.001$ ).

tumor stage, tumor grade and serum AFP level. The high nucleolin expression more frequently occurred in $\mathrm{HCC}$ tissues with advanced tumor stage $(\mathrm{P}=0.001)$, high tumor grade $(P=0.02)$ and high serum AFP level $(P=0.008)$ than those with early tumor stage, low tumor grade and low serum AFP level. In addition, nucleolin expression was not statistically associated with patient age or gender, or several of the classic markers for HCC progression, including the presence of cirrhosis and underlying liver diseases.

\section{Prognostic values of nucleolin expression in HCC}

Five-year disease-free survival was observed in 30 (23.08\%) patients, whereas in $100(76.92 \%)$ patients, disease recurred, and $88(67.69 \%)$ even died during a 5-year follow-up period. We found a trend that 5-year diseasefree survival in the group with high nucleolin expression was significantly shorter than that in the group with low expression $(\mathrm{P}<0.001$, log-rank test; Figure $2 \mathrm{~A})$. Additionally, the Kaplan-Meier plot of 5-year overall survival curves stratified by nucleolin expression was shown in Figure 2B. A significant relationship was also found between nucleolin expression and 5-year overall survival
$(\mathrm{P}<0.001, \log$-rank test, Figure 2B). Furthermore, the Cox proportional hazards model showed that nucleolin expression was an independent poor prognostic factor for both 5-year disease-free survival (hazards ratio $[\mathrm{HR}]=$ $3.696,95 \%$ confidence interval $[\mathrm{CI}]=1.662-8.138, \mathrm{P}=0.01$, Table 2) and 5 -year overall survival $(\mathrm{HR}=3.872, \mathrm{CI}=$ 1.681-8.392, $\mathrm{P}=0.01$, Table 2) in HCC.

\section{Discussion}

Early diagnosis of HCC, which is one of the most lethal malignancies, is of great clinical significance and allows the application of potentially curative treatments such as surgical resection and liver transplantation, thus improving the prognosis in patients. In this regard, accumulating studies have performed to identify biomarkers for the diagnosis and prognosis of HCC. Our current study focus on the involvement of nucleolin, which promotes cell proliferation and survival linked to carcinogenesis, in HCC. We provide the first evidence that increased expression of nucleolin protein may be correlated with poor prognosis of patients with HCC. Our data demonstrated that nucleolin may be upregulated at both

Table 2 Multivariate survival analysis of five-year overall and disease-free survival in 130 patients with hepatocellular carcinoma

\begin{tabular}{|c|c|c|c|c|c|c|}
\hline \multirow{2}{*}{ Features } & \multicolumn{3}{|c|}{ Five-year overall survival } & \multicolumn{3}{|c|}{ Five-year disease-free survival } \\
\hline & $\overline{H R}$ & $95 \% \mathrm{Cl}$ & $P$ & $\overline{H R}$ & $95 \% \mathrm{Cl}$ & $\mathbf{P}$ \\
\hline Serum AFP & 1.931 & $0.685-4.056$ & 0.063 & 1.953 & $0.615-4.273$ & 0.062 \\
\hline Tumor stage & 2.879 & $1.366-5.196$ & 0.009 & 2.686 & $1.386-6.009$ & 0.01 \\
\hline Tumor grade & 1. 563 & $0.609-4.088$ & 0.081 & 1.551 & $0.607-4.466$ & 0.086 \\
\hline Presence of cirrhosis & 1.919 & $0.738-4.102$ & 0.063 & 1.921 & $0.793-4.219$ & 0.062 \\
\hline nucleolin expression & 3.872 & $1.681-8.392$ & 0.01 & 3.696 & $1.662-8.138$ & 0.01 \\
\hline
\end{tabular}


mRNA and protein levels in HCC tissues compared to nonneoplastic liver tissues. Immunohistochemistry staining indicated that the high expression level of nucleolin protein in histological sections was markedly correlated with aggressive characteristics of human HCC including advanced tumor stages, high tumor grade and positive serum AFP, and reduced disease-free survival and overall survival of patients with HCC. We also identified nucleolin as an independent prognostic marker for poor clinical outcome.

As one of the most abundant nonribosomal proteins, nucleolin is a RNA- and protein-binding protein extensively expressed in exponentially growing eukaryotic cells [7]. Functionally, it is implicated in the several aspects of transcription, cell proliferation and growth [8]. The subcellular localizations have been found to influence the functions of nucleolin. In the nucleolus, it controls the process of DNA and RNA metabolisms; In the cytoplasm, it shuttles proteins into the nucleus and provides a post-transcriptional regulation of strategic mRNAs; And on the cell surface, it serves as an attachment protein for several ligands involved in tumorigenesis and angiogenesis [6]. Viewing this feature of nucleolin, we performed the immunohistochemistry analysis to detect its subcellular localizations in tumor cells and normal liver cells. As a result, we found that the nuclear, cytoplasmic and cytoplasmic membrane stainings of nucleolin were all detected in HCC tissues while only nuclear staining was found in nonneoplastic tissues, implying that the subcellular localization of nucleolin may change during the carcinogenesis of HCC. This change has been observed by Qiu et al. in gastric cancer [12]. According to recent studies, nucleolin acts as an oncogene and enables normal cells to become malignant through its RNA binding activity [33]. The synthesis of nucleolin is positively correlated with increased rates of cell division. Thus, its expression levels have been found to be elevated in tumors or other rapidly dividing cells and are present at low levels in normal or quiescent cells [11-16], in line with which, the Q-PCR and western blot analyses performed in the current study both showed the higher expression of nucleolin in HCC tissues than in adjacent non-neoplastic liver tissues. More importantly, the aberrant expression of nucleolin has also been demonstrated to be closely correlated with tumor progression and prognosis in several cancer types. For example, Qiu et al. [12] indicated that the high expression level of nucleolin was an independent prognostic marker for worse survival of patients with gastric cancer; Zhao et al. [13] determined that nucleolin expression independently predicted for worse survival of patients with non small cell lung cancer; Grinstein et al. [14] identified nucleolin as activator of human papillomavirus type 18 oncogene transcription in cervical cancer; High levels of nucleolin expression have also been shown to correlate with poor survival in patients with cutaneous melanoma and pediatric intracranial ependymoma $[15,16]$. In contrast, Peng et al. [34] reported that high levels of nucleolar expression of nucleolin may be associated with better prognosis in patients with stage II pancreatic ductal adenocarcinoma. Our study revealed that the increased expression of nucleolin was dramatically associated with aggressive clinicopathological features of patients with HCC, such as advance tumor stage, high tumor grade and high serum level of AFP. In the survival analysis, a high level of nucleolin expression was associated with both shorter 5-year overall survival and 5-year disease-free survival, and was an independent prognostic factor in HCC patients.

\section{Conclusion}

In conclusion, these results showed that the markedly and consistently increasing expression of nucleolin may be associated with aggressive characteristics of HCC, and implied that nucleolin expression may serve as a promising biochemical marker for predicting the clinical outcome of patients with this malignancy. Further studies are needed to investigate the precise function of nucleolin in the progression of HCC.

\section{Competing interests}

The authors declare that they have no competing interests.

\section{Authors' contributions}

GX and $X L$ carried out the experiments and drafted the manuscript; $Y L, L R$, $W Z, R B$ and DJ participated sample collection and data analysis; LB advised the study and revise the manuscript. All authors read and approved the final manuscript.

\section{Author details}

${ }^{1} 302$ Hospital of PLA, Beijing 100039, China. ${ }^{2}$ Beijing Institute of Radiation Medicine, Beijing 100850, China. ${ }^{3}$ Department of Hepatobiliary and

Pancreaticosplenic Surgery, the First Affiliated Hospital of General Hospital of PLA, Beijing 100048, China.

Received: 20 May 2014 Accepted: 23 August 2014

Published online: 18 September 2014

\section{References}

1. Jemal A, Bray F, Center MM, Ferlay J, Ward E, Forman D: Global cancer statistics. CA Cancer J Clin 2011, 61:69-90.

2. Dhir M, Lyden ER, Smith LM, Are C: Comparison of outcomes of transplantation and resection in patients with early hepatocellular carcinoma: a meta-analysis. HPB (Oxford) 2012, 14:635-645.

3. Zhu AX: Molecularly targeted therapy for advanced hepatocellular carcinoma in 2012: current status and future perspectives. Semin Oncol 2012, 39:493-502.

4. Tanaka S, Arii S: Molecular targeted therapies in hepatocellular carcinoma. Semin Oncol 2012, 39:486-492.

5. Yang H, Xiong F, Wei X, Yang Y, McNutt MA, Zhou R: Overexpression of LAPTM4B-35 promotes growth and metastasis of hepatocellular carcinoma in vitro and in vivo. Cancer Lett 2010, 294:236-244.

6. Wise JF, Berkova Z, Mathur R, Zhu H, Braun FK, Tao RH, Sabichi AL, Ao X Maeng $H$, Samaniego F: Nucleolin inhibits Fas ligand binding and suppresses Fas-mediated apoptosis in vivo via a surface nucleolin-Fas complex. Blood 2013, 121:4729-4739.

7. Koutsioumpa M, Papadimitriou E: Cell surface nucleolin as a target for anti-cancer therapies. Recent Pat Anticancer Drug Discov 2014, 9:137. 52. 
8. Schokoroy S, Juster D, Kloog Y, Pinkas-Kramarski R: Disrupting the oncogenic synergism between nucleolin and Ras results in cell growth inhibition and cell death. PLoS One 2013, 8:e75269.

9. Yang X, Xu Z, Li D, Cheng S, Fan K, Li C, Li A, Zhang J, Feng M: Cell surface nucleolin is crucial in the activation of the CXCL12/CXCR4 signaling pathway. Tumour Biol 2014, 35:333-338

10. Fujiki H, Watanabe T, Suganuma M: Cell-surface nucleolin acts as a central mediator for carcinogenic, anti-carcinogenic, and disease-related ligands. J Cancer Res Clin Oncol 2014, 140:689-699.

11. Pichiorri F, Palmieri D, De Luca L, Consiglio J, You J, Rocci A, Talabere T, Piovan C, Lagana A, Cascione L, Guan J, Gasparini P, Balatti V, Nuovo G, Coppola V, Hofmeister CC, Marcucci G, Byrd JC, Volinia S, Shapiro CL, Freitas MA, Croce CM: In vivo NCL targeting affects breast cancer aggressiveness through miRNA regulation. J Exp Med 2013, 210:951-968.

12. Qiu W, Zhou F, Zhang $Q$, Sun $X$, Shi $X$, Liang $Y$, Wang $X$, Yue L: Overexpression of nucleolin and different expression sites both related to the prognosis of gastric cancer. APMIS 2013, 121:919-925.

13. Zhao H, Huang $Y$, Xue C, Chen $Y$, Hou X, Guo Y, Zhao L, Zh H, Huang Y, Luo $Y$, Zhang L: Prognostic significance of the combined score of endothelial expression of nucleolin and CD31 in surgically resected non-small cell lung cancer. PLoS One 2013, 8:e54674.

14. Grinstein $E$, Wernet $P$ : Cellular signaling in normal and cancerous stem cells. Cell Signal 2007, 19:2428-2433.

15. Li L, Hou J, Liu X, Guo Y, Wu Y, Zhang L, Yang Z: Nucleolin-targeting liposomes guided by aptamer AS1411 for the delivery of siRNA for the treatment of malignant melanomas. Biomaterials 2014, 35:3840-3850.

16. Ridley L, Rahman R, Brundler MA, Ellison D, Lowe J, Robson K, Prebble E, Luckett I, Gilbertson RJ, Parkes S, Rand V, Coyle B, Grundy RG, Children's Cancer and Leukaemia Group Biological Studies Committee: Multifactorial analysis of predictors of outcome in pediatric intracranial ependymoma. Neuro Oncol 2008, 10:675-689.

17. Bao $H$, Song $P$, Liu $Q$, Liu $Y$, Yun $D$, Saiyin $H$, Du R, Zhang $Y$, Fan $H$, Yang $P$, Chen $X$ : Quantitative proteomic analysis of a paired human liver healthy versus carcinoma cell lines with the same genetic background to identify potential hepatocellular carcinoma markers. Proteomics Clin Appl 2009, 3:705-719.

18. Meng GZ, Xiao SJ, Zeng SE, Li YQ: Downregulation of cell-surfaceexpressed nucleolin inhibits the growth of hepatocellular carcinoma cells in vitro. Zhonghua Zhong Liu Za Zhi 2011, 33:23-27.

19. Riaz A, Memon K, Miller FH, Nikolaidis P, Kulik LM, Lewandowski RJ, Ryu RK, Sato KT, Gates VL, Mulcahy MF, Baker T, Wang E, Gupta R, Nayar R, Benson AB 3rd, Abecassis M, Omary R, Salem R: Role of the EASL, RECIST, and WHO response guidelines alone or in combination for hepatocellular carcinoma: radiologic-pathologic correlation. J Hepatol 2011, 54:695-704

20. Pirisi M, Leutner M, Pinato DJ, Avellini C, Carsana L, Toniutto P, Fabris C, Boldorini R: Reliability and reproducibility of the edmondson grading of hepatocellular carcinoma using paired core biopsy and surgical resection specimens. Arch Pathol Lab Med 2010, 134:1818-1822.

21. Durand F, Valla D: Assessment of the prognosis of cirrhosis: Child-Pugh versus MELD. J Hepatol 2005, 42:S100-S107.

22. Chen $\mathrm{CH}$, Hu FC, Huang GT, Lee PH, Tsang YM, Cheng AL, Chen DS, Wang JD, Sheu JC: Applicability of staging systems for patients with hepatocellular carcinoma is dependent on treatment method-analysis of 2010 Taiwanese patients. Eur J Cancer 2009, 45:1630-1639.

23. Livak KJ, Schmittgen TD: Analysis of relative gene expression data using real-time quantitative PCR and the 2(-Delta Delta $C(T)$ ) Method. Methods 2001, 25:402-408

24. Xu MZ, Yao TJ, Lee NP, Ng IO, Chan YT, Zender L, Lowe SW, Poon RT, Luk $\mathrm{JM}$ : Yes-associated protein is an independent prognostic marker in hepatocellular carcinoma. Cancer 2009, 115:4576-4585.

25. Guo X, Xiong L, Zou L, Zhao J: Upregulation of bone morphogenetic protein 4 is associated with poor prognosis in patients with hepatocellular carcinoma. Pathol Oncol Res 2012, 18:635-640.

26. Schmilovitz-Weiss H, Tobar A, Halpern M, Levy I, Shabtai E, Ben-Ari Z: Tissue expression of squamous cellular carcinoma antigen and Ki67 in hepatocellular carcinoma-correlation with prognosis: a historical prospective study. Diagn Pathol 2011, 6:121.

27. Hong $H$, Patonay $B$, Finley J: Unusual reticulin staining pattern in well-differentiated hepatocellular carcinoma. Diagn Pathol 2011, 6:15.

28. Fisher RA: On the interpretation of $\times 2$ from contingency tables, and the calculation of P. J R Stat Soc 1992, 85:87-94.
29. Wong KC: Chi squared test versus Fisher's exact test. Hong Kong Med J 2011, 17:427.

30. Stel VS, Dekker FW, Tripepi G, Zoccali C, Jager KJ: Survival analysis I: the Kaplan-Meier method. Nephron Clin Pract 2011, 119:c83-c88.

31. Zhang D, Quan H: Power and sample size calculation for log-rank test with a time lag in treatment effect. Stat Med 2009, 28:864-879.

32. Garcia Rl, Ibrahim JG, Zhu H: Variable selection in the cox regression model with covariates missing at random. Biometrics 2010, 66:97-104.

33. Woo HH, Baker T, Laszlo C, Chambers SK: Nucleolin mediates microRNAdirected CSF-1 mRNA deadenylation but increases translation of CSF-1 mRNA. Mol Cell Proteomics 2013, 12:1661-1677.

34. Peng L, Liang J, Wang H, Song X, Rashid A, Gomez HF, Corley LJ, Abbruzzese JL, Fleming JB, Evans DB, Wang H: High levels of nucleolar expression of nucleolin are associated with better prognosis in patients with stage II pancreatic ductal adenocarcinoma. Clin Cancer Res 2010, 16:3734-3742

\section{doi:10.1186/s13000-014-0175-y}

Cite this article as: Guo et al: Increased level of nucleolin confers to aggressive tumor progression and poor prognosis in patients with hepatocellular carcinoma after hepatectomy. Diagnostic Pathology 2014 9:175.

\section{Submit your next manuscript to BioMed Central and take full advantage of:}

- Convenient online submission

- Thorough peer review

- No space constraints or color figure charges

- Immediate publication on acceptance

- Inclusion in PubMed, CAS, Scopus and Google Scholar

- Research which is freely available for redistribution 